\title{
Improvement of finger amputation technique in the treatment of diabetic foot
}

\author{
Bogomolets National Medical University, Kyiv, Ukraine \\ Maksym Prystupiuk MD
}

\section{Introduction.}

Diabetic foot is one of the leading disabling chronic complications of diabetes. From $40 \%$ to $60 \%$ (and in some regions up to $90 \%$ ) of all non-traumatic amputations are performed in patients with diabetes. According to international epidemiological studies, the incidence of amputations reaches 206 cases per 100 thousand. In Ukraine in 2015, up to 2656 lower limb amputations were performed in patients with diabetes, which is 0.62 persons per 10 thousand of population.

\section{Methods.}

Amputations were performed in 31 diabetics with neuropathic and neuroishemic diabetic foot forms, including 11 males of $60.50 \pm 1.50$ years old and 20 females of $70.95 \pm 1.45$ years old. A control group composed 30 patients. The peculiarity of the proposed method was the application of silica sorbent on the wound after finger amputation, without suturing the wound. The next day, when the dressing was removed, the wound was debrided using ultrasonic cavitation system with continuous observation of the wound and application of vacuum therapy. The next step was plastic closure of the wound.

\section{Results.}

The average length of stay of the research patients at the hospital before a plastic closure of wound was $15.50 \pm 1.12$ days, while the duration of the control group was averaged $24.42 \pm 0.13$ days.

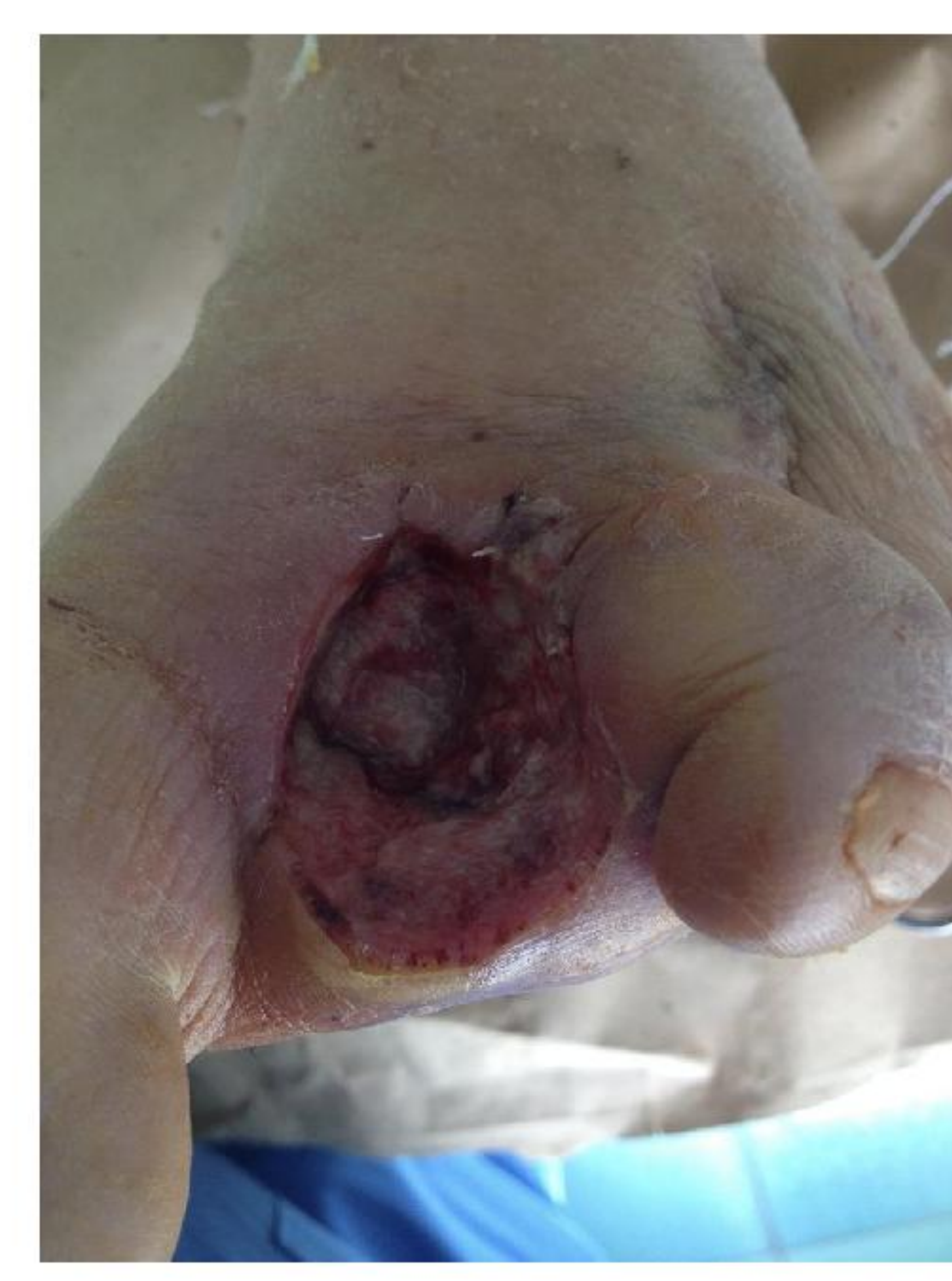

before

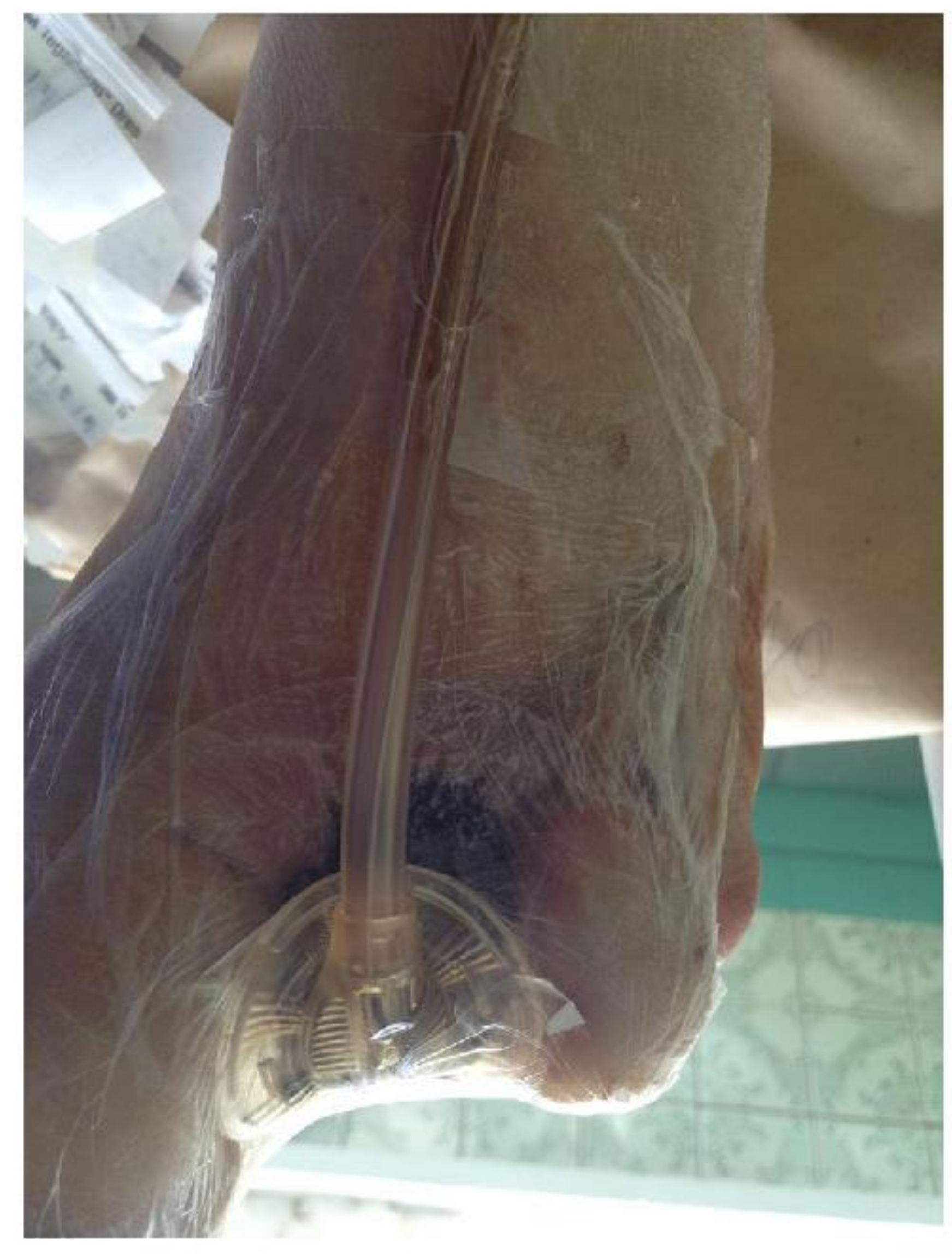

vacuum therapy

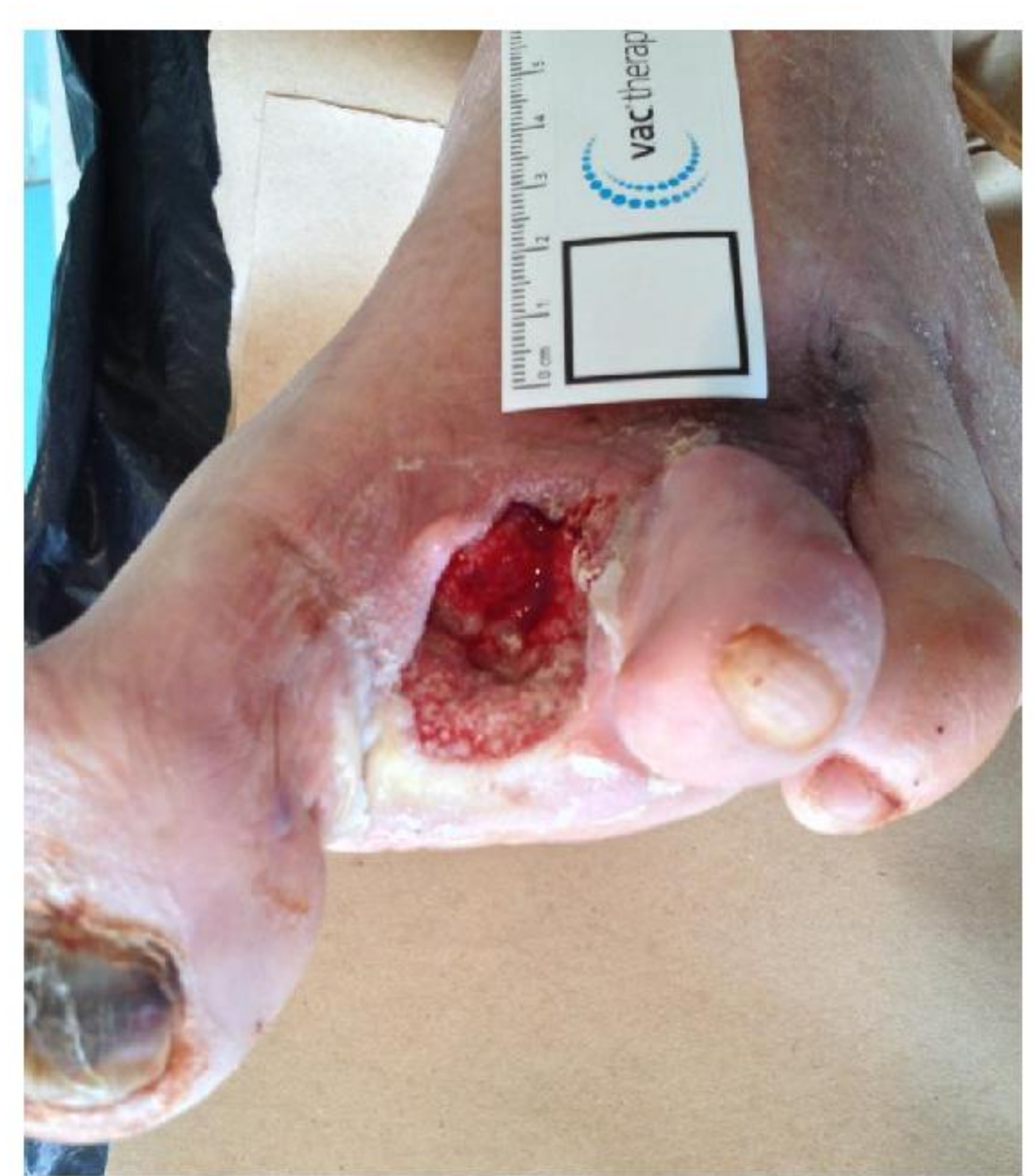

$4^{\text {th }}$ day of therapy

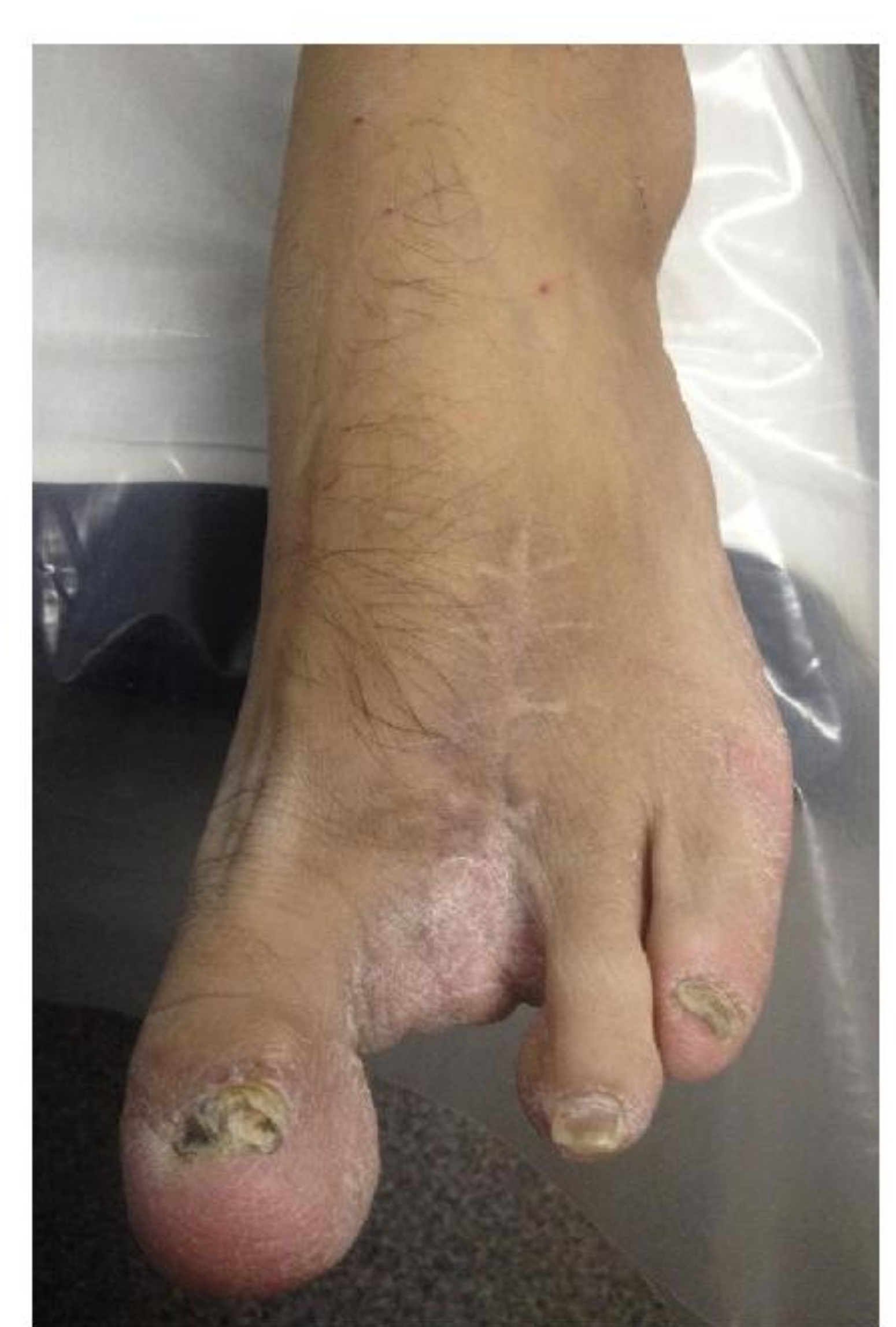

$25^{\text {th }}$ day of therapy

\section{Conclusions.}

1. Implementation of the proposed method of surgery eliminates the need for high amputations in patients with diabetic foot. 2. The proposed method of surgical treatment using the vacuum dressings in patients with diabetic foot eliminates the need for additional surgical procedures.

3. Combined surgical treatment of purulent complications of the foot using vacuum therapy helps to twice speed up cleaning of the wound and reduces surgical treatment duration in 1.6 times.

4. Improved technique of the surgical treatment of the foot with the preservation of its bearing capacity is recommended for implementation in treatment of purulent-necrotic complications of diabetic foot. 